\title{
The Global Engineer: An Implementation of Outcomes-based Accreditation Requirements
}

\author{
Jonathan M. Fishbein \\ Director, Curriculum Enhancement \& Global Engineers \\ Engineers Without Borders (Canada) \\ jonfishbein@ewb.ca
}

\begin{abstract}
The current state of the public's perception and understanding of the engineering profession, in addition to changing nature of engineering practice with the rise of the globalized economy, demands that Canadian universities change the way we train engineers. This is further reinforced by the Canadian Engineering Accreditation Board (CEAB) transitioning towards a new outcome-based framework for accreditation. At Engineers Without Borders (Canada), we have been working with Canadian universities to develop more Global Engineers, a concept that is similar to the new $C E A B$ accreditation requirements. We present our Global Engineering concept, as well as our identified implementation best practices, as a potential model to help guide universities towards outcome-based accreditation.
\end{abstract}

\section{Introduction}

The Engineering profession has the capacity to be one of the leading professions in society. Unfortunately, this is not case according to the current public perception of the profession. When asked, the public ranks the prestige of engineering in the middle, below doctors, scientists, clergy and and teachers [1]. Multiple studies have demonstrated that K-12 students and teachers view the role of the engineering profession as limited to technicians and technologists [2].

This perception represents a key challenge to the profession, which manifests itself in two major ways. Firstly, the profession's core concept of engineering as a service profession to solve problems for the betterment of society is not being communicated effectively and is not being understood by the public. This leads to the public viewing the usefulness of engineers and 'engineering solutions' being applicable to a limited domain. Secondly, this public perception has effectively limited the perceived skill set and societal value of an engineer to dealing with technical minutiae. Therefore, the profession attracts a large number of engineering students and practitioners that are proficient and excited by mathematics, science and technology furthering this stereotype.

As a result, the engineering curriculum has focused primarily on proficiency in mathematics and sciences. However, with the new outcomes-based accreditation processes being implemented by the Canadian Engineering Accreditation Board (CEAB) [3], there is pressure on the engineering curriculum to expand to include more of a societal focus, professionalism, and communication skills and demonstrate graduate competencies in this area. 
Over the past 5 years, Engineers Without Borders (Canada) (EWB) has been working with various engineering faculties across the country to help develop more Global Engineers, engineers that will take a broad view in thinking and acting on the world's most complex problems. This paper presents EWB's experiences in implementing our global engineering concepts and draws parallels to potential implementations of the new CEAB outcomes.

\section{The Need for a New Engineer}

As the world becomes more complex and interrelated, so do the problems that engineers face. Global society is facing many significant challenges, like global warming and extreme poverty. These challenges cry out for engineering input, although none are necessarily new areas for engineers. What is new is the emerging complexities of these challenges.

As well, the rise of globalization and boom in information and transportation technologies have resulted in the world becoming increasingly more interconnected. Many engineering projects are no longer constrained to a single location or even a single country. Information can flow in real time between remote locations requiring nearly instantaneous processing and response. And most importantly, the borders between disciplines have been blurred requiring engineering practice to incorporate knowledge and skills from economics, public policy, sociology and psychology. However, there is very little formal training in the engineering curriculum to deal with problems existing with this level of complexity.

Similarly, industry has observed a lack of leadership attitudes, communication skills and professional awareness in emerging engineering graduates. When surveyed, employers show a relative lack of satisfaction with these skills when compared to the technical skills of new engineering graduates [4].

\section{CEAB Outcome-based Require- ments}

Partly in response to these demands, the CEAB has revised its accreditation requirements and processes towards an outcomes-based framework [3]. This represents a shift away from a class hour accounting philosophy for accreditation, following the lead of the American Accreditation Board of Engineering and Technology (ABET), which undertook a similar shift in 2000. Additionally, outcomes-based accreditation is required to ensure continued compliance with the Washington Accord, recognizing equivalence in engineering educational requirements for licensure between the signatory countries. The CEAB is transitioning to this outcome-based accreditation process over the next five years and it will form the basis of accreditation decision in 2014.

The CEAB has proposed that graduating engineers demonstrate competency in the following outcome areas:

1. A knowledge base for engineering,

2. Problem Analysis,

3. Investigation,

4. Design,

5. Use of engineering tools,

6. Individual and team work,

7. Communication skills,

8. Professionalism,

9. Impact of engineering on society and the environment,

10. Ethics and equity,

11. Economics and project management, and

12. Life-long learning. 
In order to achieve accreditation under this new system, engineering faculties must first define institutional-specific statements for each outcome area and produce a curriculum map highlighting where in their curriculum these competencies are introduced, reinforced and mastered by their students. Faculties must create evaluation mechanisms to measure the achieved competencies of their graduates and design feedback processes to enhance learning activities in response to deficiencies.

\section{The Global Engineer}

The Global Engineer is the next generation of engineer that the EWB would like to see graduate from universities across Canada and across the world. These global engineers will take a broad view in thinking and acting to understand and propose solutions for many of the complex emerging global issues. To enable these engineers to be global leaders, they must be equipped with the core capacities to approach these challenges with thoughtfulness, ability and open minds.

Over the past three years, in collaboration with engineering faculty members from across Canada and around the world, with industrial leaders, and with engineering students, EWB has led an effort to define the global engineer. Through the focus groups conducted, the following characteristics of the global engineer have been identified.

A Global Engineer is an engineer that

A. understands the broad, bigger picture context of engineering work, including crossdisciplinary aspects, and the business and social implications;

B. has expertise in a specific field, but is comfortable in many engineering disciplines and able to work in an interdisciplinary way;

C. is a problem solver and is creative; can adapt to new situations, deal with complexity, and is skilled at systems thinking;

D. is able to collaborate on a global basis, including knowledge and/or understanding of people, culture and language, and knowledge of collaboration techniques and software;

E. is able to communicate effectively both orally and in writing in English, and is able to communicate across language and cultural differences;

F. has an understanding of sustainability efforts, and the ability to factor environmental impact and energy use characteristics into all aspects of his/her work;

G. is up to date on current world issues and emerging trends and is constantly expanding his/her skills to be able to respond to these issues appropriately;

H. has a well-developed sense of social responsibility and ethics, with due consideration in his/her personal and professional activities for the world and society; and

I. is entrepreneurial, and is prepared to work with a varying level of resources and in various types of organizations in many different roles.

Many of these skills have not traditionally been seen as part of an engineering education. While engineering and scientific principles are universally applicable, other elements (e.g. organizational, economic and environmental issues) often direct the engineering process and are key to effective engineering practice [5]. To use a practical example, engineering projects have moved from designing a bridge to designing a bridge in a developing country with an emerging democracy using local labour. Engineers need to become comfort- 
able working in the ambiguity of these complex environments with open-ended problems.

\section{Developing Global Engineers}

Through partnerships with engineering universities, we have been testing and trialling pedagogical elements in the engineering curriculum to develop and evaluate the development of Global Engineers. Below, we present three identified best practices.

\subsection{Peer Learning}

We have seen that a sense of personal ownership and control towards students learning goals have raised the level of personal responsibility and involvement with learning. As well, allowing students to research and present curriculum areas lets them explore and develop different knowledge and skills (i.e. communication, knowledge transfer, critical thinking) that are not formally emphasized in the traditional engineering curriculum.

For example, moving towards seminar-style classes from traditional lectures are one possible implementation. As well, senior students can be used to help teach concepts to junior students, facilitating learning for both groups of students in addition to establishing formal and informal mentorship relationships. Involving students in elements of course delivery not only allows students to build more of a connection to the material that they have learned, but can allow more learning on technical and nontechnical skills to be developed efficiently.

\subsection{Case Study-based Learning}

Learning through case studies allows students to explore real world, practical problems while learning the knowledge and skills necessary to resolve a specific scenario. In terms of developing Global Engineers, case studies allow students to gain experience working with complex, open-ended, and multi-disciplinary problems while learning and applying technical concepts. Additionally, case study ac- tivities can be implemented with certain roleplaying elements, allowing students to gain an appreciation for the interpersonal and teambased challenges associated with many realworld scenarios.

We have developed case studies that have been implemented in engineering course curricula at many universities across the country. These case studies investigate an engineer's role in international projects and expose students to many of the technical and nontechnical challenges associated (some course descriptions outlined on [6].)

\subsection{Outcome-based Evaluation}

Monitoring students' competency in the global engineering outcome statements is important to determining the success of the learning activities designed to develop global engineers. Demonstrated positive change in students' capabilities is taken to be a measure of a successful learning activities, and this type of progress is not recorded by current, credit-based university evaluation systems.

To implement this monitoring system, we first take a snapshot of student capabilities in a particular outcome before a learning activity. This is usually accomplished by a small classroom task or assignment that requires a student to apply the outcome (e.g. an effective oral communication task could be a simple presentation). Students' capacity for the outcome is recorded and feedback is given to identify areas for improvement. The class then proceeds, presenting the designed learning activities appropriate to enhance the outcome. At the end of the class, the same small classroom task or assignment that was given at start is given again, and the students performance is measured against the initial performance to determine the progression towards the outcome. This evaluation mechanism allows for efficient racking of students' progress towards the defined outcome areas throughout their academic 
careers.

\section{CEAB Outcome-based Accredita- tion Parallels}

EWB's goals and approach to developing Global Engineers have significant overlap with the CEAB's outcome-based accreditation requirements. The elements of greatest overlap are presented below.

\subsection{Outcome Statements}

The list of Global Engineering outcomes is quite similar to the list of CEAB outcomes. Table 1 shows the correlation between Global Engineering outcomes to the CEAB outcomes (CEAB and Global Engineering outcomes are defined in Sections 3 and 4, respectively.)

Table 1: Similarity Matrix Between Global Engineering Outcomes and CEAB Outcomes

\begin{tabular}{|c|c|c|c|c|c|c|c|c|c|}
\hline & \multicolumn{7}{|c|}{ Global Engineering Outcomes } \\
\hline $\begin{array}{c}\text { CEAB } \\
\text { Outcomes }\end{array}$ & A & B & C & D & E & F & G & H & I \\
\hline 1 & $\mathbf{x}$ & $\mathbf{x}$ & & & & & & & \\
\hline 2 & & & $\mathbf{x}$ & & & & & & \\
\hline 3 & & & $\mathbf{x}$ & & & & & & \\
\hline 4 & & $\mathbf{x}$ & $\mathbf{x}$ & & & & & & \\
\hline 5 & & $\mathbf{x}$ & & & & & & & \\
\hline 6 & & & & $\mathbf{x}$ & & & & & \\
\hline 7 & & & & & $\mathbf{x}$ & & & & \\
\hline 8 & & & & & & & & $\mathbf{x}$ & $\mathbf{x}$ \\
\hline 9 & $\mathbf{x}$ & & & & & $\mathbf{x}$ & & $\mathbf{x}$ & \\
\hline 10 & & & & & & & & $\mathbf{x}$ & \\
\hline 11 & $\mathbf{x}$ & $\mathbf{x}$ & & & & & & & $\mathbf{x}$ \\
\hline 12 & & & & & & & $\mathbf{x}$ & & \\
\hline
\end{tabular}

The advantage to the Global Engineering outcomes set is that they present a greater level of detail to guide implementation. The CEAB outcomes are meant as an evaluation mechanism for accreditation, but the definition state- ments are left to the specific institutions to create. In contrast, the Global Engineering outcomes present a smaller set of more detailed statements which have complete coverage with the $\mathrm{CEAB}$ requirements. Engineering faculties can implement the Global Engineering outcomes within their programs and be in compliance with new CEAB standards.

\subsection{Learning Processes}

One of the key challenges in transitioning to an outcomes-based accreditation model is the need to cover more concepts in an engineering curriculum that is already full. Forgoing any structural changes to engineering programs (e.g. the addition of another year,) pedagogical mechanisms need to be found that allow more material to be presented in parallel without compromising the quality of the existing curriculum.

The learning activities developed to create Global Engineers, namely peer learning and case study-based projects and assignments, can be used to help overcome this challenge. These methods expand on the traditional lecture-style teaching of universities by allowing students to be exposed additional experiences and content in parallel to existing concepts. This is similar to the experiences of many American engineering schools who found that the addition of more case study activities helped them achieve ABET outcome standards [7].

\subsection{Evaluation}

With the CEAB outcomes, universities must show that graduates possess a level of competency in each outcome area that is satisfactory to the institution. Clearly, this can not be demonstrated by marks alone.

The evaluation mechanism used to assess Global Engineering outcomes can be used as a mechanism to show students' progression to the desired CEAB outcomes. Learning portfolios in each outcome area can be developed for 
each student and their progress towards competency in each outcome can be tracked and monitored by the institutions or by the students themselves. Most importantly, the significant changes to a student's competency in an outcome can be identified and linked to particular courses and learning activities. This allows engineering faculties to monitor the effectiveness of their curriculum in near real-time allowing for continuous improvement and quick restorative action to ensure students meet accreditation before the next CEAB visit.

\section{Conclusions}

A better public understanding of engineering will help improve perceptions of the profession and may encourage more students to pursue an engineering education. Currently, the technology-centred perception results in attracting mostly technical-savvy individuals and promoting a mathematics and science heavy education, which is limiting the profession's ability to address many of the significant global challenges being faced today.

With new outcomes-based accreditation requirements being phased in by the $\mathrm{CEAB}$, partly to respond to this perception and partly to comply with the Washington accord, engineering faculties will need to adjust both elements of their curricula and pedagogy to meet these new standards. EWB's Global Engineering concept and implementation best practices can serve as an example for universities in their aim to comply with these new requirements.

EWB's Global Engineering concept is still under development. We are actively seeking partnerships with universities to enhance the concepts and outcomes presented and to further test and trial implementations of new pedagogical and evaluation elements. Over the next year, we plan to continue our work to gain further knowledge in how to effectively train engineers to better meet the demands of our global society within the engineering educa- tion system in Canada.

\section{References}

[1] Harris Interactive, "Firefighters, doctors, and nurses top list as 'most prestigious' occupations", The Harris Poll \# 58. July 26, 2006. http: //www.harrisinteractive.com/ harris_poll/index.asp?PID=685

Accessed July 8, 2009.

[2] C. Cunningham, C. Lachapelle, and A. Lindgren-Streicher, "Elementary teachers' understandings of engineering and technology.", Proceedings of the American Society for Engineering Education, Chicago, IL, 2006.

[3] Canadian Engineering Accreditation Board, "Accreditation criteria and procedures 2008," September 2008. http://www . engineerscanada.ca/e/files/ report_ceab_08_txt_only.pdf. Accessed July 8, 2009.

[4] Engineers Canada and the Canadian Council of Technologists and Technicians, "2007 Engineering and Technology Labour Market Survey," November 2008. http://etlms.engineerscanada. $\mathrm{ca} / \mathrm{media} / 2007 \% 20 \mathrm{Employer} \%$ 20.Survey20Report1.pdf. Accessed July 8, 2009.

[5] B. Newburry, "Engineering globalization: Oxymoron or opportunity?", IEEE Technology and Society Magazine, 24(3), 2005, pp. 8-15.

[6] J.M. Fishbein, "Developing Global Engineers: Incorporating International Development into the Engineering Curriculum", Proceedings of the Canadian Society for Civil Engineering Annual Conference, St. John's, NL, 2009.

[7] L.R. Lattuca, P.T. Terenzini, and J.F. Volkwein, "Engineering Change: A Study of the Impact of EC2000, Full Report," University Park, PA, 2006. 